\title{
Diameter, Vessel Thickness and Angle of Bifurcation of the Radial Artery in Ethiopian Cadavers
}

\author{
Dereje Getachew $^{1}$ Ayalew Astatkie ${ }^{2}$ Kinfe Lemma ${ }^{3}$
}

${ }^{1}$ Department of Anatomy, College of Medicine and Health Sciences, Hawassa University, Hawassa, Ethiopia

Address for correspondence Dereje Getachew, Master of Human

2 School of Public and Environmental Health, College of Medicine and Anatomy (MSc), Department of Anatomy, College of Medicine and Health Sciences, Hawassa University, Hawassa, Ethiopia, Health Sciences, Hawassa University, Hawassa, Ethiopia

${ }^{3}$ Department of Internal Medicine, College of Medicine and Health P.O. Box 1560 (e-mail: getachewdereje68@gmail.com).

Sciences, Hawassa University, Hawassa, Ethiopia

J Morphol Sci 2018;35:129-135.

\begin{abstract}
Keywords

- radial artery

- diameter

- vessel thickness

- angle of bifurcation

- Ethiopia
\end{abstract}

\section{Introduction}

The radial artery is derived from the bifurcation of the brachial artery at the apex of the cubital fossa. This vessel courses over the lateral aspect of the forearm deep to the brachioradialis muscle until its midpoint, and then becomes subcutaneous near the distal forearm. In the distal forearm, the radial artery is located immediately lateral to the tendon of the flexor carpi radialis and directly anterior to the pronator quadratus muscle. To get into the hand region, it passes from the wrist joint laterally through the anatomical snuffbox between the heads of the first dorsal interosseous received

February 2, 2016

accepted

August 3, 2018

published online

August 31, 2018
DOI https://doi.org/

10.1055/s-0038-1669905. ISSN 2177-0298.
Copyright $(2018$ by Thieme Revinter

Publicações Ltda, Rio de Janeiro, Brazil
License terms

(ㄷ) (i) $\ominus$ (5) 
muscle. In the forearm and hand area, it gives numerous smaller generations to supply nearby structures. Along its course, it is accompanied by a similarly named vein, the radial vein. ${ }^{1}$

The radial artery is smaller than the ulnar artery and is more a continuation of the brachial artery. Instead of arising as a branch of the brachial artery, it may arise from the axillary artery or more proximally than usual from the medial side of the brachial artery and then cross over the brachial artery to enter the forearm. However, in the routine clinical practice, variations of the radial artery are one of the main reasons for technical failure. ${ }^{2}$ According to one study, ${ }^{3}$ variations are most common in the upper limbs, and happen with a frequency of $20 \%$. This can be observed in most dissection rooms. Radial artery also shows a constant pattern with only a few variations being described in part of the literature. $^{4}$ Unusual arterial variations are frequently noticed, and experience with those variations may be of much help in the clinical practice, particularly with the expanding use of upper limb arteries in surgical procedures, such as radial forearm flap, coronary artery grafting, and in preoperative angiographic studies. $^{3}$

The technique of using the radial artery as a coronary artery bypass graft was introduced by Carpentier. ${ }^{5}$ Two years after the initial series was published in 1973, another paper published by Carpentier claimed that there was a high risk associated with the procedure, which led to the abandonment of the use of the technique worldwide. The papers published in 1992 and 1993 by the French surgeon Christophe Acar ${ }^{6}$ reported that after 104 patients underwent a coronary angiography, made $100 \%$ revealing of the radial artery. This resulted in a consensus regarding the need for the renewal of this technique, since several authors ${ }^{7}$ agree that there is no reduction in strength and flow to the forearm due to the alternative blood supply from anastomoses.

The transradial approach is commonly used for cannulation, coronary angiography, and bypass graft because it is preferred by clinicians due to its technical ease and less likelihood of complications. ${ }^{8}$ In addition, according to a research conducted by Onorati et al, ${ }^{9}$ radial artery graft is not affected by age. According to Sajja et al, ${ }^{10,11}$ there still is no uniformity regarding the harvest technique.

Transradial catheterization or angioplasty was introduced in the past 10 years as a treatment for heart attack. The methods are widely accepted due to an alternative blood supply from the ulnar artery to minimize the frequency of local complications. The concept is that a tube (catheter) with a tiny balloon at the end is inserted through the radial artery in the upper limb and directed into the artery that is blocked. Once it reaches the location of the blockage, the balloon is inflated, flattening the fatty deposit and opening the artery. Angioplasty uses a special safety device that catches particles that sometimes dislodge from the side of the artery. ${ }^{12}$

When compared with the transfemoral approach for cardiac catheterization, the transradial approach has merits because: the dual blood supply limits the potential for limb threatening ischemia; it is advantageous for patients with severe occlusive aortoiliac disease and for patients with diffi- culty in lying down (such as those with back pain and obesity); the vessels are easily compressible; it has less chance of local nerve injury; the radial approach allows earlier patient ambulation and will likely cost less; it is associated with less frequent vascular complication; and, to date, randomized trials suggest that patients prefer the radial approach. ${ }^{13}$

While harvesting the radial artery for coronary artery bypass graft, the diameter, the variation and the length of the artery should be taken into consideration. The small caliber (internal diameter) of the radial artery and the variety of equipment available for radial artery access, such as needle, wire, and sheath, and the basic knowledge about the morphology, the variation, the diameter, and the thickness of the wall of the radial artery are very important for clinical practitioners, especially for vascular and plastic surgeons, to perform with precision a percutaneous coronary intervention ( $\mathrm{PCI}$ ) using catheterization. However, evidence on these variables and parameters are lacking in Ethiopia. Therefore, the present study was conducted to determine the internal and external diameters, the vessel thickness, and the angle of bifurcation of the ulnar and radial arteries among adult Ethiopian cadavers.

\section{Materials and Methods}

This was a descriptive study involving the dissection of 78 upper limbs (39 right, 39 left) of the cadavers of 18 adult females and 21 adult males in the age range between 25 and 77 years old whose radial arteries and its branches were exposed. The present study was undertaken in the anatomy laboratories of three different Medical Colleges in Ethiopia: the College of Medicine and Health Sciences of the Hawassa University, the College of Medicine and Health Sciences of the Addis Ababa University, and the College of Health Sciences and Medicine of the Jimma University.

The measurements of the radial artery were taken at its origin from the brachial artery, at the cubital fossa, and at the wrist joint. All measurements were repeated three times, and the average was calculated. Prior to the measurement, the upper limb was carefully dissected to expose the muscles in the area, especially the brachioradialis, where the initial measurements of the external diameter, of the internal diameter and of the wall thickness were taken. The dissection continued down over the anterior aspect of the forearm to expose the distal part of the radial artery where the second set of measurements of the external diameter, of the internal diameter, and of the wall thickness was taken.

The level of bifurcation of the brachial artery was also determined regarding the head of radius. The angle of origin of the radial and ulnar arteries from the brachial artery was measured at the cubital fossa. An imaginary line drawn along the brachial artery was used as a reference point to measure the angles. The angle of the radial artery was measured first, followed by the angle of the ulnar artery ( - Fig. $\mathbf{1}$ ).

The procedures used in the measurements were in line with the approved protocols of the anatomy laboratories of the aforementioned universities. A digital vernier caliper (Model AD-5765A-150, A\&D company,limited, Tokyo, Japan) was used to measure the internal diameter, the external diameter, and 


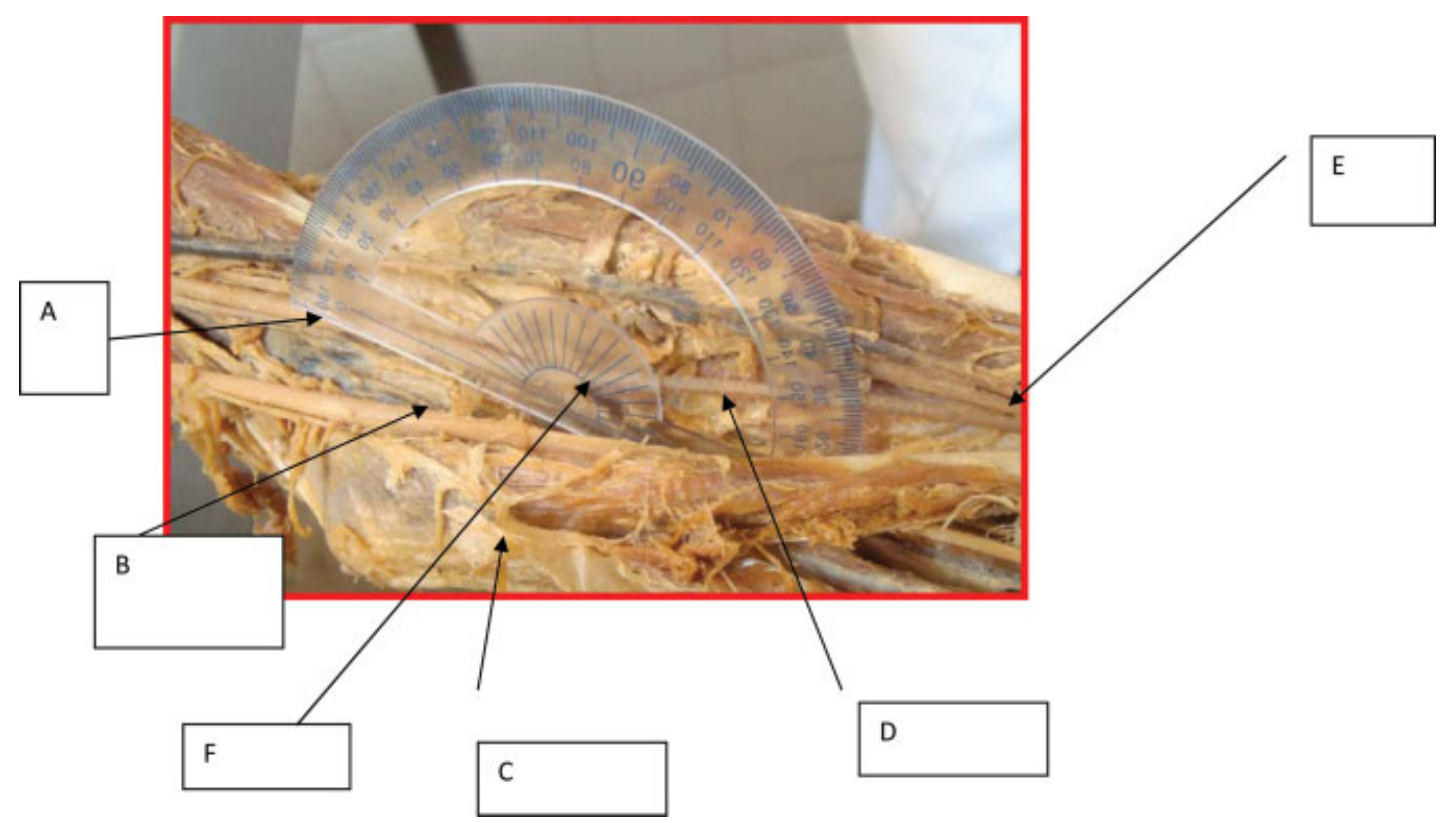

Fig. 1 A diagram showing the measurement of the angle of bifurcation of the brachial artery into the radial and ulnar arteries. A - brachial artery; B - median nerve; C - medial epicondyle; D - protractor; E - radial artery; F - angle of bifurcation.

the wall thickness of the arteries. A protractor was used to measure the angle of bifurcation of the brachial artery into the radial and ulnar arteries. The vernier caliper is a precise instrument that can be used to measure with extreme accuracy the internal diameter, the external diameter, and the wall thickness. ${ }^{14}$ The example shown in - Fig. $\mathbf{2}$ is a digital caliper; the diameters were interpreted from its scale.

The data were collected over a period of two consecutive years, as there was a shortage of cadavers in Ethiopian Medical Schools. All cadavers were considered for the present study, but those that had anomalies and/or variations were excluded. The data were entered and analyzed using the Statistical Package for the Social Sciences (SPSS, SPSS Inc., Chicago, IL,
US) software, version 16.0. The means \pm standard deviations (SDs) of the different measurements were computed. We used the paired samples $t$-test to compare the differences in arterial diameter, in thickness, and in the angle of bifurcation between the right and left limbs. The independent samples $t$-test was used to compare the aforementioned parameters between females and males. A $p$-value $\leq 0.05$ was considered statistically significant.

\section{Results}

A total of 39 adult cadavers was studied, of which 21 (53.8\%) were male and 18 (46.2\%) were female. The number of limbs

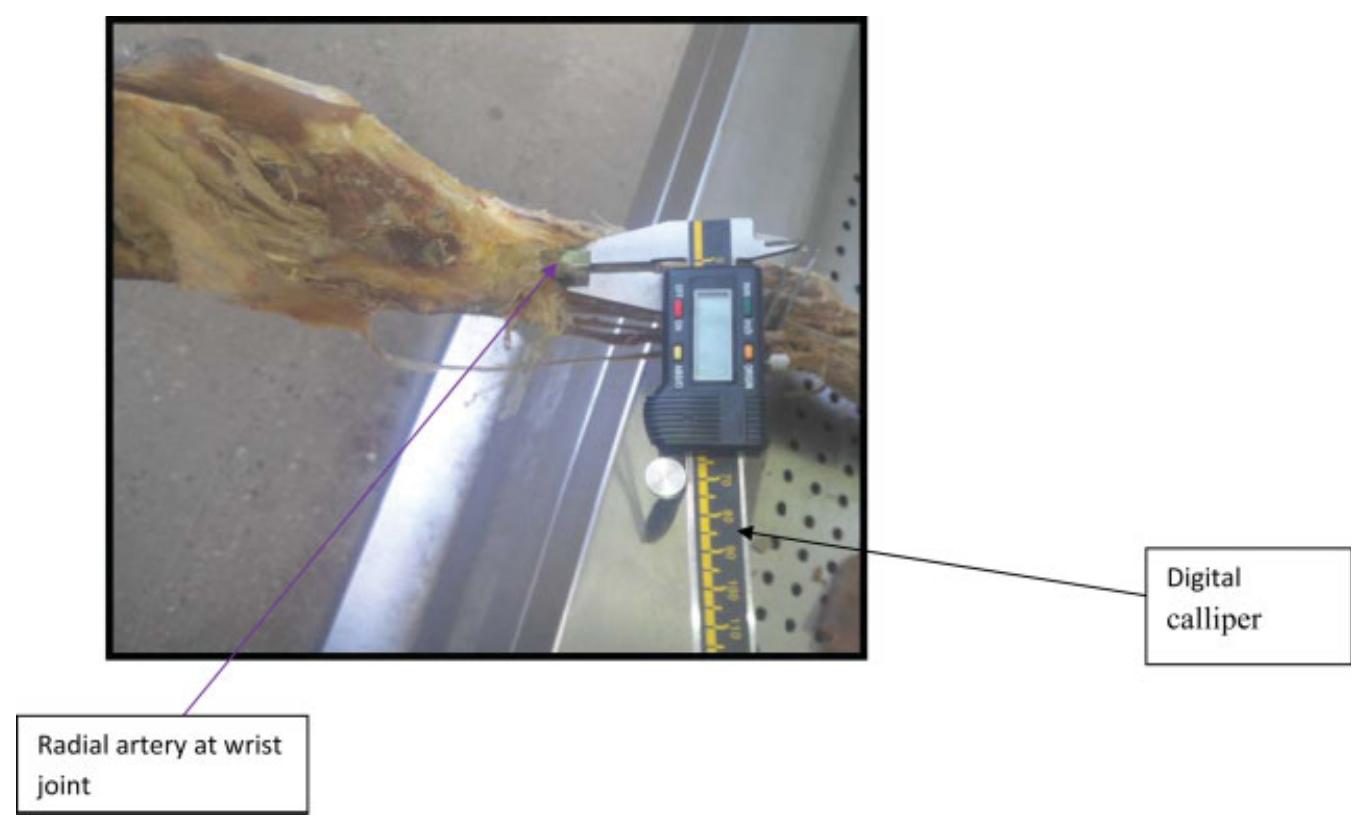

Fig. 2 A diagram showing the digital vernier caliper while measuring the external diameter at the wrist joint. 
studied was 78 (39 right and 39 left limbs). The age of the cadavers ranged from 25 to 77 years, with a mean \pm SD age of $58.05 \pm 15.264$ years old.

\section{Radial Artery Diameter}

The mean \pm SD of the external diameter of the right radial artery at the cubital fossa was $4.40 \pm 1.26 \mathrm{~mm}$, while the mean \pm SD of the external diameter of the left radial artery at the cubital fossa was $4.44 \pm 1.51 \mathrm{~mm}$. However, this difference was not statistically significant ( $t$-test [t] [degree of freedom $(\mathrm{df})=38]=-0.33 ; p=0.75)$.

The mean \pm SD of the external diameter of the right radial artery at the wrist joint was $3.24 \pm 0.79 \mathrm{~mm}$, while the mean \pm SD of the external diameter of the left radial artery at the wrist was $3.06 \pm 0.85 \mathrm{~mm}$. Here again, this difference was not statistically significant $(\mathrm{t}[\mathrm{df}=38]=-1.57 ; p=0.13$ ).

The mean \pm SD of the internal diameter of the right radial artery at the cubital fossa was $3.79 \pm 1.44 \mathrm{~mm}$, while the mean \pm SD of the internal diameter of the left radial artery at the cubital fossa was $3.79 \pm 1.78 \mathrm{~mm}$. However, this difference was not statistically significant $(\mathrm{t}[\mathrm{df}=38]=-0.06 ; p=0.96)$.

The mean \pm SD of the internal diameter of the right radial artery at the wrist joint was $2.79 \pm 1.10 \mathrm{~mm}$, while the mean \pm SD of the internal diameter of the left radial artery at the wrist joint was $2.66 \pm 0.94 \mathrm{~mm}$. This difference was not statistically significant $(\mathrm{t}[\mathrm{df}=38]=-1.20 ; p=0.24$ ). See - Tables $\mathbf{1}$ and $\mathbf{2}$.

When comparing the diameters between males and females, the mean \pm SD of the external diameter of the right radial artery at the cubital fossa in males was $4.45 \pm 1.35$, while in females itwas $4.36 \pm 1.18$. However, this difference was not statistically significant $(\mathrm{t} \quad[\mathrm{df}=37]=0.22$; $p=0.31)$. Similarly, the mean \pm SD of the external diameter of the left radial artery at the cubital fossa in males was $4.41 \pm 1.5 \mathrm{~mm}$, while in females it was $4.49 \pm 1.51 \mathrm{~mm}$. Similarly, this difference was not statistically significant $(\mathrm{t}$ [df $=37]=-0.16 ; p=0.69$ ).

Table 1 The mean \pm standard deviation of the external diameter, internal diameter and wall thickness of the radial artery taken at the cubital fossa and at the wrist joint of the right and left sides of the whole sample

\begin{tabular}{|c|c|c|c|c|}
\hline \multirow{2}{*}{$\begin{array}{l}\text { Radial } \\
\text { artery }\end{array}$} & \multirow[t]{2}{*}{ Side } & \multicolumn{3}{|l|}{ Mean \pm SD } \\
\hline & & $\begin{array}{l}\text { External } \\
\text { diameter } \\
(\mathrm{mm})\end{array}$ & $\begin{array}{l}\text { Internal } \\
\text { diameter } \\
(\mathrm{mm})\end{array}$ & $\begin{array}{l}\text { Thickness } \\
(\mathrm{mm})\end{array}$ \\
\hline \multicolumn{5}{|c|}{ Cubital fossa } \\
\hline & Right & $4.40 \pm 1.26$ & $3.79 \pm 1.44$ & $0.37 \pm 0.22$ \\
\hline & Left & $4.44 \pm 1.51$ & $3.79 \pm 1.78$ & $0.34 \pm 0.23$ \\
\hline \multicolumn{5}{|c|}{ Wrist joint } \\
\hline & Right & $3.24 \pm 0.79$ & $2.79 \pm 1.10$ & $0.25 \pm 0.22$ \\
\hline & Left & $3.06 \pm 0.85$ & $2.66 \pm 0.94$ & $0.28 \pm 0.24$ \\
\hline
\end{tabular}

Abbreviations: SD, Standard deviation; mm, millimeters.
The mean \pm SD of the internal diameter of the right radial artery at the cubital fossa in males was $3.66 \pm 1.65 \mathrm{~mm}$, and, in females, it was $3.93 \pm 1.16 \mathrm{~mm}$. This difference was statistically significant ( $\mathrm{t}[\mathrm{df}=35.73]=-0.59 ; p=0.015$ ). Similarly, the mean \pm SD of the internal diameter of the left radial artery at the cubital fossa in males was 3.48 (2.08), while in females it was $4.17 \pm 1.29 \mathrm{~mm}$. This difference was statistically significant $(\mathrm{t}[\mathrm{df}=33.94]=-1.25 ; p<0.004)$.

The mean \pm SD of the external diameter of the right radial artery at the wrist joint in males was $3.36 \pm 0.85 \mathrm{~mm}$, and, in females, it was $3.10 \pm 0.73$, a difference that was not statistically significance $(\mathrm{t}[\mathrm{df}=37]=1.00 ; p=0.71$ ). Similarly, the mean \pm SD of the external diameter of the left radial artery at the wrist joint in males was $3.10 \pm 0.78 \mathrm{~mm}$, while in females it was $3.01 \pm 0.95 \mathrm{~mm}$. This difference was also not statistically significant ( $[\mathrm{df}=37]=0.35 ; p=0.63$ ).

The mean \pm SD of the internal diameter of the right radial artery at the wrist joint in males was $2.83 \pm 1.27 \mathrm{~mm}$, while in females it was $2.74 \pm 0.65 \mathrm{~mm}$. This difference was not statistically significant ( $\mathrm{t}[\mathrm{df}=37]=0.25 ; p=0.09$ ). Similarly, the mean \pm SD of the internal diameter of the left radial artery at the wrist joint in males was $2.56 \pm 1.06 \mathrm{~mm}$, while in females it was $2.77 \pm 0.80 \mathrm{~mm}$. Here again, this difference was not statistically significant $(\mathrm{t} \quad[\mathrm{df}=37]=-0.68$; $p=0.12$ ). See - Table 3.

\section{Radial Artery Thickness}

The mean \pm SD of the wall thickness of the right radial artery at the cubital fossa was $0.37 \pm 0.22 \mathrm{~mm}$, while the mean \pm SD of the wall thickness of the left radial artery at the cubital fossa was $0.34 \pm 0.23 \mathrm{~mm}$. However, the difference in wall thickness between the right and the left radial arteries was not statistically significant $(\mathrm{t}[\mathrm{df}=38]=0.96 ; p=0.34$ ). Similarly, the mean \pm SD of the wall thickness of the right radial artery at the wrist joint was $0.25 \pm 0.22 \mathrm{~mm}$, while the mean (SD) of the wall thickness of the left radial artery at the wrist joint was $0.28 \pm 0.24$. This difference, however, was not statistically significant $(\mathrm{t} \quad[\mathrm{df}=38]=-0.79$; $p=0.43$ ). See - Tables 1 and 2.

Comparing males and females, the mean \pm SD of the wall thickness of the right radial artery at the cubital fossa in males was $0.37 \pm 0.22 \mathrm{~mm}$, while in females it was $0.36 \pm 0.21 \mathrm{~mm}$. This difference was not statistically significant ( $\mathrm{t}[\mathrm{df}=37]=0.09 ; p=0.93$ ) Similarly, the mean $\pm \mathrm{SD}$ of the wall thickness of the left radial artery at the cubital fossa for males was $0.29 \pm 0.91 \mathrm{~mm}$, while for females it was $0.37 \pm 0.27 \mathrm{~mm}$. However, this difference was not statistically significant $(\mathrm{t}[\mathrm{d} \mathrm{f}=37]=-1.07$; $p=0.14$ ). See - Table 3 .

The mean \pm SD of the wall thickness of the right radial artery at the wrist joint in males was $0.26(0.21) \mathrm{mm}$, and, in females, it was $0.25(0.23) \mathrm{mm}$. This difference, however, was not statistically significant $(\mathrm{t}[\mathrm{df}=37]=0.23 ; p=0.61$ ). Likewise, the mean \pm SD of the wall thickness of the left radial artery at the wrist joint in males was $0.22 \pm 0.19 \mathrm{~mm}$, while in females it was $0.35 \pm 0.28 \mathrm{~mm}$. This difference was statistically significant $(\mathrm{t} \quad[\mathrm{df}=37]=-1.69 ; \quad p=0.03)$. See - Table 3. 
Table $2 T$-test for equality of means at 95\% confidence interval of the difference in the external diameter, the internal diameter and the wall thickness between the right and left limbs

\begin{tabular}{|l|l|l|l|l|l|}
\hline Pair & $\begin{array}{l}\text { Mean } \\
\text { difference }\end{array}$ & $\begin{array}{l}\text { Standard } \\
\text { deviation }\end{array}$ & t-test & df & p-value \\
\hline $\begin{array}{l}\text { External diameter of the radial artery at the } \\
\text { cubital fossa in mm (right and left) }\end{array}$ & -0.04 & 0.74 & -0.33 & 38 & 0.75 \\
\hline $\begin{array}{l}\text { Internal diameter of the radial artery at the } \\
\text { cubital fossa in mm (right and left) }\end{array}$ & -0.01 & 0.71 & -0.06 & 38 & 0.96 \\
\hline $\begin{array}{l}\text { Thickness of the radial artery at the cubital fossa } \\
\text { in mm (right and left) }\end{array}$ & 0.03 & 0.19 & 0.96 & 38 & 0.34 \\
\hline $\begin{array}{l}\text { External diameter of the radial artery at the wrist } \\
\text { joint in mm (right and left) }\end{array}$ & 0.17 & 0.69 & 1.57 & 38 & 0.12 \\
\hline $\begin{array}{l}\text { Internal diameter of the radial artery at the wrist } \\
\text { joint in mm (right and left) }\end{array}$ & 0.13 & 0.68 & 1.19 & 38 & 0.24 \\
\hline $\begin{array}{l}\text { Thickness of the radial artery at the wrist joint } \\
\text { in mm (right and left }\end{array}$ & -0.03 & 0.23 & -0.79 & 38 & 0.43 \\
\hline
\end{tabular}

Abbreviations: $\mathrm{df}$, degree of freedom; mm, millimeters.

Table 3 The mean \pm standard deviation of the external diameter, the internal diameter, and thickness of the radial artery taken at the cubital fossa and at the wrist joint of male and female cadavers

\begin{tabular}{|l|l|l|l|l|l|l|}
\hline Radial artery & Sex & Side & $\mathbf{n}$ & \multicolumn{2}{l|}{ Mean \pm SD } \\
\cline { 3 - 7 } & & & & $\begin{array}{l}\text { External } \\
\text { diameter }(\mathrm{mm})\end{array}$ & $\begin{array}{l}\text { Internal } \\
\text { diameter (mm) }\end{array}$ & $\begin{array}{l}\text { Wall thickness } \\
(\mathrm{mm})\end{array}$ \\
\hline \multirow{5}{*}{ Cubital } & Male & Right & 21 & $4.45 \pm 1.35$ & $3.66 \pm 1.65$ & $0.37 \pm 0.22$ \\
\cline { 2 - 7 } & Female & Right & 18 & $4.36 \pm 1.18$ & $3.93 \pm 1.16$ & $0.36 \pm 0.21$ \\
\cline { 2 - 7 } & Male & Left & 21 & $4.41 \pm 1.5$ & $3.48 \pm 2.08$ & $0.29 \pm 0.91$ \\
\cline { 2 - 7 } & Female & Left & 18 & $4.49 \pm 1.51$ & $4.17 \pm 1.29$ & $0.37 \pm 0.27$ \\
\hline \multirow{5}{*}{ Wrist joint } & Male & Right & 21 & $3.36 \pm 0.85$ & $2.83 \pm 1.27$ & $0.26 \pm 0.21$ \\
\cline { 2 - 7 } & Female & Right & 18 & $3.10 \pm 0.73$ & $2.74 \pm 0.65$ & $0.25 \pm 0.23$ \\
\cline { 2 - 7 } & Male & Left & 21 & $3.10 \pm 0.78$ & $2.56 \pm 1.06$ & $0.22 \pm 0.19$ \\
\cline { 2 - 7 } & Female & Left & 18 & $3.01 \pm 0.95$ & $2.77 \pm 0.80$ & $0.35 \pm 0.28$ \\
\hline
\end{tabular}

Abbreviations: $\mathrm{n}$, number of cadavers; SD, standard deviation; mm, millimeters.

\section{Radial Artery Bifurcation Angle}

The origin of the right radial artery from the brachial artery at the apex of the cubital fossa had angles ranging from 21 to $81^{\circ}$, while the origin angle of the left radial artery ranged from 20 to $85^{\circ}$. The mean \pm SD of the angle of bifurcation of the right radial artery was $39.94^{\circ}\left(11.19^{\circ}\right)$. while of the angle of bifurcation of the left radial artery was $40.25^{\circ}\left(11.80^{\circ}\right)$. This difference, however, was not statistically significant ( $\mathrm{t}[\mathrm{df}=38]=-0.453 ; p=0.65)$. See - Table 4.

The mean \pm SD of the angle of origin of the right radial artery in males was $41.95^{\circ}\left(13.96^{\circ}\right)$, and, in females, it was $37.61^{\circ}\left(6.32^{\circ}\right)$. However, this difference was not statistically significant ( $\mathrm{t}[\mathrm{df}=37]=1.22 ; p=0.31$ ). Similarly, the mean \pm SD of the angle of origin of the left radial artery in males was $42.75^{\circ}\left(14.74^{\circ}\right)$, while in females it was $37.33^{\circ}$ $\left(6.25^{\circ}\right)$. This difference was not statistically significant $(\mathrm{t}[\mathrm{df}=37]=1.45 ; p=0.10)$. See - Table 5 .
Table 4 Angle of the brachial artery at its bifurcation into the radial and ulnar arteries at the apex of the cubital fossa

\begin{tabular}{|l|l|l|l|l|l|l|}
\hline Side & $\mathbf{n}$ & Range & Minimum & Maximum & Mean & SD \\
\hline $\begin{array}{l}\text { Right } \\
\text { angle }\end{array}$ & 39 & $60^{\circ}$ & $21^{\circ}$ & $81^{\circ}$ & $39.94^{\circ}$ & $11.20^{\circ}$ \\
\hline $\begin{array}{l}\text { Left } \\
\text { angle }\end{array}$ & 39 & $65^{\circ}$ & $20^{\circ}$ & $85^{\circ}$ & $40.25^{\circ}$ & $11.80^{\circ}$ \\
\hline
\end{tabular}

Abbreviations: $n$, number of cadavers; SD, standard deviation.

\section{Discussion}

To our knowledge, no previous study has been conducted in Ethiopia regarding the morphology of the radial artery, particularly diametric studies, because the field of PCI was introduced very recently in the country. Moreover, we have 
Table 5 Angle of bifurcation of the brachial artery into the radial and ulnar arteries at the apex of the cubital fossa by sex

\begin{tabular}{|l|l|l|l|l|}
\hline Sex & $\mathbf{n}$ & Side & Mean & SD \\
\hline Male & 21 & Right & $41.95^{\circ}$ & $13.96^{\circ}$ \\
\hline Female & 18 & Right & $37.61^{\circ}$ & $6.32^{\circ}$ \\
\hline Male & 21 & Left & $42.75^{\circ}$ & $14.74^{\circ}$ \\
\hline Female & 18 & Left & $37.33^{\circ}$ & $6.25^{\circ}$ \\
\hline
\end{tabular}

Abbreviations: n, number of cadavers; SD, standard deviation.

found that there are less cadaveric studies directly related to the diametric study of the radial artery. Therefore, the present cadaveric study is our first step forward to expand our studies on patients using Doppler ultrasound.

During the early embryonic development and the growth of the upper limb, the variation of vessels is based on the growth or the regression of the bud plexus. As a result, any faults in the development process of the bud plexus lead to many variations in the arterial origins, as well as in the arterial courses. The incidence of vascular upper limb variations ranges between 9 and $18.5 \%{ }^{15}$ The variability of radial artery in origin and course is very common, which may affect the diagnosis and management procedures, such as surgical interventions. Therefore, it is valuable for clinicians to know the diameter, the thickness, the angle of origin, and the variations of the radial artery, because several surgical and invasive interventions are performed in the cubital and wrist regions. This knowledge may lead to a reduction in medical mistakes. Therefore, learning the anatomical vascular variations is of paramount medical significance.

In the present study, the angle of bifurcation of the brachial artery into the radial and ulnar arteries at the apex of the cubital fossa of the right limb ranges from 21 to $81^{\circ}$, and in the left limb it ranges from 20 to $85^{\circ}$. According to a study on the cubital fossa by Al-Sowayigh et al, ${ }^{16}$ the radial artery usually arises at the level of the neck of radius in $21.7 \%$ of the individuals. However, it may arise either before or after the level of the neck of radius in $11.7 \%$ or in $6 \%{ }^{16}$ of the individuals respectively. It usually arises after the intercondylar line in $92 \%{ }^{17}$ of the individuals, but it may arise before the intercondylar line in $10 \%$ of the individuals. ${ }^{16}$ Therefore, the radial artery arises from the brachial or from the axillary artery before the antecubital fossa, which is referred to as a high origin. According to another study, ${ }^{18}$ the angle of the radial artery regarding the brachial artery ranges between 80 and $300^{\circ}$. This angle was found to be wider in males and on the right side. ${ }^{18}$

In the present cadaveric study, the means of the right and left external diameters of the radial artery at the cubital fossa were $4.40 \mathrm{~mm}$ and $4.44 \mathrm{~mm}$ respectively, while the means of the right and left external diameters of the radial artery at the wrist joint (1-2 $\mathrm{cm}$ proximal to the styloid process of the anterior surface of the radius) were $3.24 \mathrm{~mm}$ and $3.06 \mathrm{~mm}$ respectively. This finding shows that the radial artery decreases in size as it moves from the proximal to the distal part. Our finding is in line with the findings by $\mathrm{Nasr}^{14}$ and Waseem et al. ${ }^{18}$

Which showed a mean diameter of $3.1 \mathrm{~mm}$ and 3.6 , respectively, at the wrist joints? According to the aforementioned article, the external diameter of the radial artery at the cubital fossa matches with the external diameter of 10-French (Fr) sheaths, which have an external diameter of $4.0 \mathrm{~mm}$, and an internal diameter of $3.4 \mathrm{~mm}$. However, this finding is not in line with the finding of a study conducted among patients using ultrasound Doppler, which showed that the use of guiding catheters $\geq 7 \mathrm{Fr}$ in the radial artery is feasible in selected patients. ${ }^{19}$

In the present study, the mean of the right internal diameter of the radial artery at the cubital fossa in males was $3.66 \mathrm{~mm}$, while in females it was $3.93 \mathrm{~mm}$, and the difference was statistically significant. Similarly, the mean of the left internal diameter of the radial artery at the cubital fossa in males was $3.48 \mathrm{~mm}$, ande, in females, it was $4.17 \mathrm{~mm}$, again a statistically significant difference. Since currently more focus is being given to the distal part of the radial artery for coronary intervention, we have also measured the diameter of the radial artery at the wrist joint. The results showed that the mean of the internal diameter of the right radial artery at the wrist joint $(2.79 \mathrm{~mm})$ was not significantly different from the mean of the internal diameter of the left radial artery $(2.66 \mathrm{~mm})$ at the wrist joint. The present study is in line with the study conducted by Prakash et $\mathrm{al}^{20}$ in India among a sample of 50 radial arteries of 25 cadavers ( 20 males and 5 females), in which the mean \pm SD luminal diameter at its termination $2 \mathrm{~cm}$ proximal to the styloid process, just above the wrist joint, was reported to be $2.14 \pm 0.28 \mathrm{~mm}$. Our results are also in line with a Doppler ultrasonographic study of 117 subjects $^{21}$ that reported the mean \pm SD diameters of the right and left radial arteries to be $2.35 \pm 0.49 \mathrm{~mm}$, and $2.29 \pm 0.48 \mathrm{~mm}$ respectively. Moreover, Pal et $\mathrm{al}^{21}$ reported a mean \pm SD diameter of $2.325 \pm 0.4 \mathrm{~mm}$ for the radial arteries.

Moreover, in the present study, the mean \pm SD of the wall thickness of the right radial artery at the wrist joint was $0.25 \pm 0.22 \mathrm{~mm}$, while the mean \pm SD of the wall thickness of the left radial artery at the wrist joint was $0.28 \pm 0.24 \mathrm{~mm}$. This result is a bit higher than what was reported by a previous study that reported a wall thickness of $0.15 \pm 0.10 \mathrm{~mm}$ and of $0.16 \pm 0.13 \mathrm{~mm}$ for the right and left limbs respectively. ${ }^{18}$ In the interpretation of our results, it must be noted that as it was a cadaveric study, we could not measure confounding factors such as weight, body surface area, body mass index, arm circumference, and risk factors of cardiovascular diseases. Therefore, the comparison of the mean diameters, thicknesses and angles of the bifurcations were unadjusted for the aforementioned confounders. This might have introduced some biases in our results.

\section{Conclusion}

Given the many advantages of the transradial approach for coronary catheterization and intervention, knowledge of the morphology of the radial arteries in a given population is of 
paramount importance for informed decision making. The primary reason is fear of complications and procedural failure related to the smaller size of the radial arteries in comparison with that of femoral arteries, the most important parameter being the internal diameter. From the study of a total of 78 dissected radial artery specimens (both right- and left-sided; 21 male and 18 female cadavers) and comparing the present study with previous works, it can be concluded that the diameter of the radial artery of the Ehiopian population is comparable with that of other populations, and that its size is adequate for the commonly used $10 \mathrm{Fr}$ radial catheters. Therefore, the radial artery can be safely considered as a route for transradial coronary interventions in Ethiopian patients. However, this sample was taken from cadaveric specimens, and we could not consider confounding factors and the prevalence of anomalies such as tortuosity, richness in collateral branches, and the length of the radial artery. Therefore, we recommend further studies, preferably on live subjects. We also recommend the study of factors possibly associated with variations in the morphology of the radial arteries.

\section{Acknowledgment}

We are thankful for the Anatomy Laboratory technician of Hawassa University, Mr. Checkol Biresaw. We are thankful for the Addis Ababa and the Jimma University Anatomy laboratory technicians. We would like to extend our thanks to those not mentioned by name but who offered a valuable contribution for the completion of the present research work.

\section{References}

1 Moore KL. Clinically Orientated Anatomy, Lippincott Williams and Wilkins.1999

2 Jelev L, Surchev L. Radial artery coursing behind the biceps brachii tendon: significance for the transradial catheterization and a clinically oriented classification of the radial artery variations. Cardiovasc Intervent Radiol 2008;31(05):1008-1012

3 Shen S, Hong MK. A rare case of bilateral variations of upper limb arteries: brief review of nomenclature, embryology and clinical applications. Surg Radiol Anat 2008;30(07):601-603

4 Loukas M, Louis RG Jr, Almond J, Armstrong T. A case of an anomalous radial artery arising from the thoracoacromial trunk. Surg Radiol Anat 2005;27(05):463-466

5 Carpentier A, Guermonprez JL, Deloche A, Frechette C, DuBost C. The aorta-to-coronary radial artery bypass graft. A technique avoiding pathological changes in grafts. Ann Thorac Surg 1973;16 (02):111-121 Doi: 10.1016/S0003-49759(10)65825-0

6 Acar C, Jebara VA, Portoghese M, et al. Revival of the radial artery for coronary artery bypass grafting. Ann Thorac Surg 1992;54(04): 652-659, discussion 659-660 Doi: 16/003-4975(92)91007-V

7 Acar C, Ramsheyi A, Pagny JY, et al. The radial artery for coronary artery bypass grafting: clinical and angiographic results at five years. J Thorac Cardiovasc Surg 1998;116(06):981-989 Doi: 10.1016/S00022-5223(98)70050-9

8 Mizukoshi K, Shibasaki M, Amaya F, et al. Ultrasound evidence of the optimal wrist position for radial artery cannulation. Can J Anaesth 2009;56(06):427-431

9 Onorati F, Pezzo F, Comi MC, et al. Radial artery graft function is not affected by age. J Thorac Cardiovasc Surg 2007;134(05): 1112-1120 Doi: 10.1016/j.jtcvs.2007.06.007

10 Sajja LR, Mannam G, Sompalli S. Extrafascially harvested radial artery in CABG: technique of harvest, complications, and midterm angiographic patency. J Card Surg 2005;20(05):440-448

11 Sajja LR, Mannam G, Pantula NR, Sompalli S. Role of radial artery graft in coronary artery bypass grafting. Ann Thorac Surg 2005;79 (06):2180-2188

12 Vassilev D, Smilkova D, Gil R. Ulnar artery as access site for cardiac catheterization: anatomical considerations. J Interv Cardiol 2008; 21(01):56-60

13 Aptecar E, Pernes JM, Chabane-Chaouch M, et al. Transulnar versus transradial artery approach for coronary angioplasty: the PCVICUBA study. Catheter Cardiovasc Interv 2006;67(05):711-720

14 Wee LK, Hwee TN. Vernier caliper and micrometer computer models using Easy Java Simulation and its pedagogical design feature-ideas to augment learning with real instruments. Phys Educ 2014;49(05):493-501

15 Ciervo A, Kahn M, Pangilinan AJ, Dardik H. Absence of the brachial artery: report of a rare human variation and review of upper extremity arterial anomalies. J Vasc Surg 2001;33(01):191-194 Doi: $10.1067 /$ mva.2001.112212

16 Al-Sowayigh MA, Zaki AI, El-Haggagy AA, Abdel Aal IH, Badawoud $\mathrm{MH}$. Anatomical variation of brachial artery bifurcation. Saudi Med J 2013;34(09):908-912

17 Nasr AY. The radial artery and its variations: anatomical study and clinical implications. Folia Morphol (Warsz) 2012;71(04):252-262

18 Waseem AL, Getachew D, Roger S. The clinical significance of radial artery morphology in artificial arterial-venous fistula for hemodialysis. Indian J Soc Res 2015;11(01):24-29

19 Saito S, Ikei H, Hosokawa G, Tanaka S. Influence of the ratio between radial artery inner diameter and sheath outer diameter on radial artery flow after transradial coronary intervention. Catheter Cardiovasc Interv 1999;46(02):173-178

20 Prakash KG, Saniya K. A Study On Radial Artery In Cadavers And Its Clinical Importance. Int J Med Res Helath Sci 2014;3(02):254-262

21 Pal R, Rajeev B, Monika R. A Descriptive Comparison of Diameter of Radial and Ulnar Arteries Using Doppler Ultrasonography. Indian J Basic Appl Med Res 2014;3(03):373-379 